\title{
Acid Phosphatase
}

National Cancer Institute

\section{Source}

National Cancer Institute. Acid Phosphatase. NCI Thesaurus. Code C120022.

A family of phosphatases that add monophosphates to substrates. The optimal pH for activity of these enzymes is below 7 . 